\title{
Utilização de Probiótico, Ácido Orgânico e Antibiótico em Dietas para Coelhos em Crescimento: Ensaio de Digestibilidade, Avaliação da Morfometria Intestinal e Desempenho
}

\author{
Andrea Cristiane Michelan ${ }^{1}$, Cláudio Scapinello ${ }^{2}$, Maria Raquel Marçal Natali ${ }^{3}$, Antonio Cláudio \\ Furlan $^{2}$, Eduardo Shiguero Sakaguti ${ }^{2}$, Haroldo Garcia Faria ${ }^{4}$, Maurício Luís da Rosa Santolin ${ }^{5}$, \\ Anielle Basílio Hernandes 5
}

\begin{abstract}
RESUMO - Três experimentos, um ensaio de digestibilidade, avaliação morfométrica intestinal e desempenho, foram conduzidos para avaliar os efeitos da adição às dietas, do Calsporin ${ }^{\circledR}(0,03 \%)$, do ácido fumárico $(1,5 \%)$ e da bacitracina de zinco com $15 \%$ de atividade $(0,10 \%)$, em separado ou em combinações, sobre a utilização da matéria seca, proteína bruta, fibra em detergente neutro e energia bruta, a análise morfométrica do jejuno e o desempenho de coelhos em crescimento. No ensaio de digestibilidade, 64 coelhos da raça Nova Zelândia Branco, metade de cada sexo, com 50 dias de idade, foram distribuídos em um delineamento inteiramente casualizado, com oito tratamentos e oito repetições. A adição de qualquer dos aditivos, em separado ou combinados, às dietas de coelhos não influenciou a utilização da matéria seca, matéria orgânica, proteína bruta, fibra em detergente neutro e energia bruta. Para a análise morfométrica do jejuno, foram abatidos 100 coelhos da raça Nova Zelândia Branco, sendo quatro no início do experimento, aos 35 dias de idade e, em seguida, quatro animais por tratamento, aos 50, 60 e 75 dias de idade. A inclusão de qualquer aditivo às dietas, em separado ou combinados, não demonstrou efeito sobre a espessura da túnica mucosa, da túnica muscular externa e da parede total do jejuno de coelhos em qualquer das idades estudadas. Contudo, a espessura da túnica mucosa diminuiu linearmente com a idade. Para o ensaio de crescimento, foram utilizados 176 coelhos da raça Nova Zelândia Branco, metade de cada sexo, no período de 35 a 75 dias de idade, distribuídos em um delineamento inteiramente casualizado, com oito tratamentos, 11 repetições e dois animais por unidade experimental. Não houve efeito da adição de qualquer dos aditivos, em separado ou em combinações sobre o desempenho no período de 35 aos 50 dias de idade. Para o período total do experimento, o melhor desempenho foi obtido com os animais recebendo dietas com inclusão de ácido fumárico, ácido fumárico + bacitracina de zinco e com a dieta contendo os três aditivos. Tanto o peso, como o rendimento de carcaça, foram maiores para os animais alimentados com as dietas, contendo ácido fumárico ou ácido fumárico + bacitracina de zinco. Não houve efeito dos tratamentos sobre o peso do fígado, rins e coração.
\end{abstract}

Palavras-chave: ácido fumárico, bacitracina de zinco, calsporin ${ }^{\circledR}$, digestibilidade, desempenho, jejuno, morfometria intestinal

\section{Utilization of Probiotic, Organic Acid and Antibiotic in Diets for Growing Rabbits. Essay of Digestibility, Evaluation of Intestinal Morphometry and Performance}

ABSTRACT - Three experiments, an essay of digestibility, other of morphometrical intestinal evaluation and of performance were carried out to evaluate the effects of inclusion of Calsporin ${ }^{\circledR}(0,03 \%)$, fumaric acid (1,5\%) and zinc bacitracin with $15 \%$ of activity $(0,10 \%)$ in diets, separated or combined, on utilization of dry matter, crude protein, neutral detergent fiber, gross energy and the morphometrical jejunal analysis and the essay performed of growing rabbits. For the digestibility essay 64 White New Zealand rabbits were used, half of each sex, 50 days old, distributed on a completly randomized design with eight treatments and eight replicates. There was no difference for the digestibility coefficients of dry matter, organic matter, crude protein, neutral detergent fiber and gross energy among the treatments. For the morphometrical jejunal analysis, 100 White New Zealand rabbits were slaughtered, four in the begining of the experiment, with 35 days old, and four animals per treatment at 50,60, and 75 days old. The inclusion of the additives in the diet, separated or combined, had no effect on the jejunal wall, muscularis external tunica and the total wall morphometry of the growing rabbits. However the thickness of mucosal tunic decreased linearly with the age of rabbits. For the performed essay, 176 White New Zealand rabbits were used, half of each sex, from 35 to 75 days old, allocated in a completely randomized design, with eight treatments, 11 replicates and two animals for each replicate. The inclusion of the additives, separated or combined, had no effect on the performance from 35 to 50 days old. In the total experimental period, the best performance was observed in the animals fed with diets containing fumaric acid, fumaric acid + zinc bacitracin and the diets containing the three additives. The weight and yield carcass, were higher to the animals fed with the addition of fumaric acid or fumaric acid + zinc bacitracin in their diets. There were no effects of the treatments on the liver, kidneys and heart weight.

Key Words: calsporin ${ }^{\circledR}$, digestibility, fumaric acid, intestinal morphometry, jejunun, performance, zinc bacitracin

\footnotetext{
1 Aluna de Doutorado do Programa de Pós-Graduação em Zootecnia - UEM - Maringá, PR. E.mail: amichelan@yahoo.com.br

2 Professores do Departamento de Zootecnia - UEM - Maringá - PR. E.mail: cscapinello@uem.br

3 Professora do Departamento de Ciências Morfofisiológicas - UEM - Maringá, PR.

4 Zootecnista do Biotério Central - UEM - Maringá, PR.

5 Bolsistas de Iniciação Científica - CNPq.
} 


\section{Introdução}

A produção animal vem se adaptando às crescentes exigências e técnicas de um setor da agroindústria extremamente competitivo e a um mercado consumidor cada vez mais exigente com a qualidade dos produtos. Neste sentido, é cada vez mais intensa a preocupação com as condições sob as quais os animais são criados e as implicações que isso pode acarretar à qualidade do produto final. Dentro desse contexto, estudos vêm sendo realizados com o uso de probióticos, ácidos orgânicos e, em doses subterapêuticas, os antibióticos, entre outros, objetivando melhorar a produção animal, sem deixar resíduos nas carcaças.

Entre as diferentes fases fisiológicas por que passa o coelho a partir do nascimento, o período próximo à desmama, entre 30 e 50 dias de idade, vem merecendo especial atenção por parte de pesquisadores. Desordens digestivas, freqüentemente observadas neste período, podem estar relacionadas à maturação dos processos digestivos, às mudanças do hábito alimentar, ao aumento do consumo de alimentos sólidos e às características nutricionais das rações utilizadas durante este período (Laplace, 1978; Gidenne, 1997).

Melhor compreensão dos processos fisiológicos do trato digestivo e o uso de aditivos que possam melhorar as condições desse meio, favorecendo a manutenção de uma micropopulação benéfica aos processos de digestão e controlando a mortalidade que, normalmente, é elevada no período da desmama, podem trazer enormes ganhos econômicos.

De acordo com De Blas (1984), o uso de aditivos nas rações, capazes de melhorar o estado sanitário e o fisiológico do animal, podem minimizar o problema nesta fase de crescimento.

Segundo Fuller (1989), os probióticos são suplementos alimentares à base de microrganismos vivos que afetam beneficamente o animal hospedeiro, promovendo o balanço da microbiota intestinal.

Utilizando probiótico (Lacto-Sacc ${ }^{\circledR}$ ) e ácido orgânico (Acid Pak-4-Way) para coelhos em crescimento, em uma série de quatro experimentos, Hollister et al. (1989) observaram melhora na conversão alimentar e redução na mortalidade causada por enterite, quando estes produtos foram adicionados às rações.

Lambertini et al. (1990), utilizando um probiótico composto por Bacillus subtilis à dieta de coelhos em crescimento, não encontraram influência deste sobre o desempenho, chegando a questionar a sua utilização como promotor de crescimento. Já Fritts et al. (2000) obtiveram melhora no desempenho de frangos, quando adicionaram às rações o probiótico Calsporin$10^{\circledR}$, também composto por Bacillus subtilis, o que demonstra a especificidade dos probióticos, aliado a outros fatores que interferem na resposta dos animais.

Os ácidos orgânicos atuam diminuindo o $\mathrm{pH}$ intestinal e melhorando a atividade da pepsina do estômago. Com a redução do pH intestinal, diminui também a proliferação de E. coli e outros microrganismos patógenos, os quais competiriam com o animal pelos nutrientes, além de causarem inúmeros distúrbios no trato gastrointestinal (Cromwell, 1989).

Yamani et al. (1992) observaram que a suplementação de dietas com o probiótico Lacto-Sacc ${ }^{\circledR}(1 \mathrm{~g} / \mathrm{kg})$ melhorou a digestibilidade da fibra bruta, o peso vivo ganho de peso diário, aumentou a taxa de respiração e a temperatura retal e diminuiu o consumo de ração, melhorando, assim, a conversão alimentar. O Acid Pak-4-Way (0,5 g/L), adicionado na água de beber, por sua vez, melhorou a digestibilidade da fibra bruta, aumentou a taxa de respiração e o total de proteína no plasma. O rendimento de carcaça, no entanto, não foi afetado pela suplementação, tanto do probiótico como do acidificante.

Estudando o efeito de ácido fumárico em rações de coelhos em crescimento, Scapinello et al. (1997) encontraram que a adição de 2,0\% de ácido fumárico se mostrou eficaz na melhora do desempenho, no período de 40 a 80 dias de idade. Em um outro experimento, Scapinello et al. (1998) observaram que a adição de ácido acético ou fumárico às rações não influenciaram o desempenho de coelhos em crescimento.

O uso de antibióticos pode inibir a proliferação de microrganismos sensíveis a estas drogas, proporcionando condições favoráveis ao crescimento de populações benéficas ao meio do trato digestivo. Este aspecto pode levar, de acordo com Zuanon et al. (1998), à melhora no desempenho produtivo de frangos de corte.

Abdel-Samee (1995) adicionou às dietas de coelhos, Avoparcin (200 ppm), Flavomicina (125 ppm) e Bacitracina de zinco (150 ppm) e dois tipos de probióticos, Bospro (2500 ppm) e Lacto-Sacc ${ }^{\circledR}$ (2000 ppm). Os animais que receberam dietas suplementadas com antibiótico ou probiótico apresentaram maior ganho médio diário e consumo de ração e menor temperatura retal $\left(-0,3^{\circ} \mathrm{C}\right)$ e taxa respiratória $(-10 \%)$. A taxa de mortalidade decres-

R. Bras. Zootec., v.31, n.6, p.2227-2237, 2002 
ceu de 33 para $16 \%$, diminuindo, também, a incidência de enterite, em relação à dieta controle.

O fornecimento de probiótico, ácido orgânico e/ou antibiótico resulta, segundo Pollman (1986), em uma mudança benéfica na microflora intestinal, com uma redução na população de $E$. coli em eqüinos. O autor também cita que os probióticos e ácidos orgânicos propiciam uma mudança no $\mathrm{pH}$ intestinal. Este efeito, provavelmente, está relacionado a certas propriedades dos microrganismos, em produzir ácido lático e ácido acético, tornando o meio inadequado à proliferação de E. coli, além da propriedade dos probióticos de aderência ao epitélio intestinal, com subsequente redução da liberação de toxinas pela E. coli. Segundo este autor, a presença de microrganismos patogênicos provoca lesões e espessamento das paredes do trato gastrointestinal, possivelmente decorrente da ação de toxinas que liberam nestes locais.

Alguns componentes da dieta e o conteúdo da microbiota do trato digestivo podem levar a um espessamento da parede intestinal, prejudicando a absorção e diminuindo a quantidade de nutrientes disponíveis ao animal (Loddi, 1998).

Segundo Macari \& Maiorka (2000), o desenvolvimento da mucosa intestinal é estimulado através de agentes tróficos. Entre eles, prebióticos, frutuoligossacarídeos e probióticos favorecem o seu desenvolvimento, por permitirem maior sanidade na mucosa intestinal, através de processos denominados de exclusão competitiva.

Yu \& Chiou (1997) estudaram o desenvolvimento da mucosa intestinal de coelhos, na fase de crescimento, da desmama até à idade de 16 semanas e concluíram que a mucosa intestinal cresceu linearmente até oito semanas de idade e que, a partir desta idade até 16 semanas, não havia diferença significativa no seu desenvolvimento.

A ação positiva dos antibióticos deve-se à sua influência sobre a flora intestinal, regulando o equilíbrio microbiano, controlando as infecções subclínicas e potencializando a absorção de nutrientes (De Blas, 1984).

Avaliando a adição de plasma animal $(4,0 \%)$ e antibiótico (100 ppm Bacitracina de zinco +60 ppm Apramicina), associados ou não, em dietas para coelhos recém-desmamados, Gutiérrez et al. (2000) verificaram que a adição de plasma animal e antibiótico, em separado, às dietas aumentou a altura do vilo e profundidade de cripta do jejuno, sendo que o mesmo não ocorreu quando esses produtos foram usados em associação.

R. Bras. Zootec., v.31, n.6, p.2227-2237, 2002
Os objetivos do presente trabalho foram avaliar a suplementação de dietas, com probiótico (Calsporin$10^{\circledR}$ Bacillus subtilis $10^{10}$ células viáveis por grama), ácido orgânico (ácido fumárico) e antibiótico (bacitracina de zinco) associados ou não, sobre a eficiência de utilização de nutrientes, as características morfométricas da parede do jejuno e o desempenho e características de carcaça de coelhos, no período de 35 a 75 dias de idade.

\section{Material e Métodos}

Três experimentos foram conduzidos no Setor de Cunicultura da Fazenda Experimental de Iguatemi, da Universidade Estadual de Maringá.

\section{Ensaio de digestibilidade}

Para o ensaio de digestibilidade, foram utilizados 64 animais, 32 fêmeas e 32 machos, com 50 dias de idade, da raça Nova Zelândia Branco, alojados individualmente em gaiolas de metabolismo, providas de bebedouro automático, comedouro semi-automático e dispositivo para coleta das fezes. O delineamento foi inteiramente casualizado, com oito tratamentos e oito repetições. Os tratamentos consistiram de uma dieta referência, formulada de acordo com as exigências para coelhos em crescimento (Lebas, 1989) e outras sete dietas, em que a adição de probiótico (Calsporin ${ }^{\circledR}$ Bacillus subtilis $10^{10}$ cepa: C3102), ácido orgânico (ácido fumárico) e antibiótico (bacitracina de zinco) foi feita em substituição a um inerte, adicionado à dieta referência (Tabela 1).

O premix vitamínico-mineral utilizado era desprovido de promotor de crescimento, coccidiostático ou antibiótico, com o objetivo de evitar interferências destes produtos nos processos digestivos dos animais.

O ensaio de digestibilidade teve duração de 14 dias, sendo 10 dias para adaptação às gaiolas e às dietas e quatro dias para coleta de fezes, seguindo o Método de Referência Europeu para Experimentos de Digestibilidade in vivo (Perez et al., 1995). As rações, peletizadas a seco, e a água foram fornecidas à vontade durante as duas fases do experimento.

As fezes de cada animal foram coletadas em sua totalidade, uma vez ao dia, no período da manhã, acondicionadas em sacos plásticos e armazenadas em congelador a $-10^{\circ} \mathrm{C}$.

Posteriormente, ao final do experimento, as fezes de cada animal foram secas em estufa de ventilação forçada a $55^{\circ} \mathrm{C}$, durante 72 horas. Em seguida, as 
Tabela 1 - Composição percentual e química das dietas experimentais

Table 1 - Percentual and chemical composition of the experimental diets

\begin{tabular}{|c|c|c|c|c|c|c|c|c|c|}
\hline \multirow[t]{2}{*}{$\begin{array}{l}\text { Ingrediente } \\
\text { Ingredient }\end{array}$} & & \multicolumn{8}{|c|}{$\begin{array}{c}\text { Dietas experimentais } \\
\text { Experimental diets }\end{array}$} \\
\hline & & Controle & D2 & D3 & D4 & D5 & D6 & D7 & D8 \\
\hline Milho & $\mathrm{kg}$ & 28,87 & 28,87 & 28,87 & 28,87 & 28,87 & 28,87 & 28,87 & 28,87 \\
\hline Corn & & & & & & & & & \\
\hline $\begin{array}{l}\text { Farelo de soja } \\
\text { Soybean meal }\end{array}$ & $\mathrm{kg}$ & 13,00 & 13,00 & 13,00 & 13,00 & 13,00 & 13,00 & 13,00 & 13,00 \\
\hline $\begin{array}{l}\text { Farelo de trigo } \\
\text { Wheat meal }\end{array}$ & $\mathrm{kg}$ & 19,00 & 19,00 & 19,00 & 19,00 & 19,00 & 19,00 & 19,00 & 19,00 \\
\hline $\begin{array}{l}\text { Feno de alfafa } \\
\text { Alfalfahay }\end{array}$ & $\mathrm{kg}$ & 25,00 & 25,00 & 25,00 & 25,00 & 25,00 & 25,00 & 25,00 & 25,00 \\
\hline $\begin{array}{l}\text { Feno de aveia } \\
\text { Oat hay }\end{array}$ & $\mathrm{kg}$ & 10,00 & 10,00 & 10,00 & 10,00 & 10,00 & 10,00 & 10,00 & 10,00 \\
\hline $\begin{array}{l}\text { Sal comum } \\
\text { Salt }\end{array}$ & $\mathrm{kg}$ & 0,40 & 0,40 & 0,40 & 0,40 & 0,40 & 0,40 & 0,40 & 0,40 \\
\hline $\begin{array}{l}\text { Fosfato bicálcico } \\
\text { Dicalcium phosphate }\end{array}$ & $\mathrm{kg}$ & 0,50 & 0,50 & 0,50 & 0,50 & 0,50 & 0,50 & 0,50 & 0,50 \\
\hline $\begin{array}{l}\text { Calcário } \\
\text { Limestone }\end{array}$ & $\mathrm{kg}$ & 1,00 & 1,00 & 1,00 & 1,00 & 1,00 & 1,00 & 1,00 & 1,00 \\
\hline $\begin{array}{l}\text { DL-Metionina } \\
\text { DL-Methionine }\end{array}$ & $\mathrm{kg}$ & 0,10 & 0,10 & 0,10 & 0,10 & 0,10 & 0,10 & 0,10 & 0,10 \\
\hline $\begin{array}{l}\text { Mist. Vit+Min }{ }^{1} \\
\text { Premix vit }+ \text { min. }\end{array}$ & $\mathrm{kg}$ & 0,50 & 0,50 & 0,50 & 0,50 & 0,50 & 0,50 & 0,50 & 0,50 \\
\hline $\begin{array}{l}\text { Areia } \\
\text { Sand }\end{array}$ & $\mathrm{kg}$ & 1,63 & 1,60 & 0,13 & 1,53 & 0,10 & 1,50 & 0,07 & - \\
\hline $\begin{array}{l}\text { Calsporin }^{\circledR} \\
\text { Acido fumárico }\end{array}$ & $\begin{array}{l}\mathrm{kg} \\
\mathrm{kg}\end{array}$ & - & $\begin{array}{c}0,03 \\
-\end{array}$ & 1,50 & - & $\begin{array}{l}0,03 \\
1,50\end{array}$ & $\begin{array}{c}0,03 \\
-\end{array}$ & 1,50 & $\begin{array}{l}0,03 \\
1,50\end{array}$ \\
\hline $\begin{array}{l}\text { Fumaric acid } \\
\text { Bacitracina de Zn }\end{array}$ & $\mathrm{kg}$ & - & - & - & 0,10 & - & 0,10 & 0,10 & 0,10 \\
\hline $\begin{array}{l}\text { Zinc bacitracin } \\
\text { Total }\end{array}$ & $\mathrm{kg}$ & 100 & 100 & 100 & 100 & 100 & 100 & 100 & 100 \\
\hline $\begin{array}{l}\text { Composição analis } \\
\text { Analyzed compositio }\end{array}$ & & & & & & & & & \\
\hline $\begin{array}{l}\text { Matéria seca } \\
\text { Dry matter }\end{array}$ & $\%$ & 90,78 & 90,80 & 91,25 & 91,45 & 91,71 & 91,49 & 91,36 & 91,66 \\
\hline $\begin{array}{l}\text { Proteína bruta } \\
\text { Crude protein }\end{array}$ & $\%$ & 17,26 & 17,84 & 17,72 & 17,27 & 17,21 & 16,99 & 17,43 & 17,89 \\
\hline $\begin{array}{l}\text { FDN } \\
N D F\end{array}$ & $\%$ & 33,66 & 36,81 & 32,98 & 30,88 & 34,60 & 36,76 & 33,12 & 31,23 \\
\hline $\begin{array}{l}\text { FDA } \\
A D F\end{array}$ & $\%$ & 19,57 & 19,90 & 17,37 & 18,46 & 18,21 & 20,34 & 18,26 & 17,43 \\
\hline $\begin{array}{l}\text { Cálcio } \\
\text { Calcium }\end{array}$ & $\%$ & 0,73 & 0,73 & 0,76 & 0,75 & 0,77 & 0,71 & 0,73 & 0,76 \\
\hline $\begin{array}{l}\text { Fósforo } \\
\text { Phosphorus }\end{array}$ & $\%$ & 0,42 & 0,46 & 0,46 & 0,45 & 0,46 & 0,45 & 0,46 & 0,47 \\
\hline $\begin{array}{l}\mathrm{pH} \\
\text { Energia digestível } \\
\text { Digestible energy }\end{array}$ & $\begin{array}{l}\text { Acidez } \\
\mathrm{kcal} / \mathrm{kg}\end{array}$ & $\begin{array}{l}5,66 \\
2627\end{array}$ & $\begin{array}{l}5,64 \\
2614\end{array}$ & $\begin{array}{l}4,79 \\
2638\end{array}$ & $\begin{array}{l}5,65 \\
2616\end{array}$ & $\begin{array}{l}4,77 \\
2639\end{array}$ & $\begin{array}{l}5,62 \\
2616\end{array}$ & $\begin{array}{l}4,74 \\
2667\end{array}$ & $\begin{array}{l}4,75 \\
2656\end{array}$ \\
\hline $\begin{array}{l}1 \text { Nuvital, composição } \\
\text { mg; Vit B6, } 200 \text { mg; } \\
\text { mg; Manganês, } 8.6 \\
\text { Vitamin -mineral premi } \\
\text { B6,200 mg; Vit B12,2. } \\
\text { Zinc, } 12.000 \text { mg; lodin } \\
\text { ه FATEC. }\end{array}$ & $\begin{array}{l}00.000 \\
\text { ntotênic } \\
\text { lodo, } 64 \\
\text { Vit } A, 60 \\
00 \mathrm{mg} ; \mathrm{Ch}\end{array}$ & $\begin{array}{l}\text { D, } 100.00 \\
00 \text { mg; Co } \\
\text { Selênio, } 16 \\
\text { Ul; Vit D, } 10 \\
70.000 \mathrm{mg} ;\end{array}$ & $\begin{array}{l}\text { UI; Vit } \\
\text { a, } 70.0 \\
\text { ig; Me } \\
000 \text { UI; } \\
n, 8.000\end{array}$ & $\begin{array}{l}8.00 \\
\mathrm{mg} \\
\text { nina, } \\
E, 8.0 \\
g ; C o\end{array}$ & $\begin{array}{l}\text {; Vit K } \\
0,8.0 \\
.000 \mathrm{r} \\
\text { g; Vit K }\end{array}$ & $\begin{array}{l}00 \mathrm{~m} \\
\mathrm{ng} ; \mathrm{C} \\
\text { Antio } \\
\text { Omg; }\end{array}$ & $\begin{array}{l}\mathrm{B} 1,4 \\
1.20 \\
\text { nte , } \\
1,400 \mathrm{n} \\
\mathrm{Omg} ; \mathrm{n}\end{array}$ & $\begin{array}{l}\mathrm{mg} ; \\
\mathrm{g} ; \mathrm{C} \\
00 \mathrm{n} \\
\text { /it B2 }\end{array}$ & $\begin{array}{l}32,600 \\
\text { to, } 200 \\
\mathrm{mg} ; \mathrm{Vit} \\
600 \mathrm{mg} ;\end{array}$ \\
\hline
\end{tabular}


amostras foram processadas em moinho com peneira de $1 \mathrm{~mm}$ e submetidas a análises da matéria seca (MS), da matéria orgânica (MO), da proteína bruta (PB), da fibra detergente neutro (FDN) e da energia bruta (EB), de acordo com Silva (1990). Em seguida, foram calculados os coeficientes de digestibilidade aparente de matéria seca (CDMS), matéria orgânica (CDMO), proteína bruta (CDPB), fibra detergente neutro (CDFDN) e energia bruta (CDEB) das dietas experimentais.

A determinação de $\mathrm{pH}$ das rações foi feita segundo a metodologia adaptada de Phillip \& Fellner (1992), utilizando-se $25 \mathrm{~g}$ de ração moída a $1 \mathrm{~mm}$ em um recipiente com $100 \mathrm{~mL}$ de água destilada; deixando em repouso por 1 hora e, em seguida, após homogeneização, foi feita a medição do pH, utilizando-se um pHmetro.

\section{Morfometria intestinal}

Para avaliar os efeitos da adição de Calsporin ${ }^{\circledR}$ Bacillus subtilis cepa: C3102, ácido orgânico (ácido fumárico) e antibiótico (bacitracina de Zinco) sobre a morfometria do intestino delgado (jejuno), foram abatidos 100 animais: quatro animais foram abatidos no início do experimento ( 35 dias de idade) e, em seguida, quatro animais/ tratamento aos 50,60 e, no final da fase experimental, aos 75 dias de idade.

Deve-se salientar que, a partir dos 60 dias de idade, todos os animais que restaram, independentemente dos tratamentos, passaram a receber a dieta controle, sem qualquer dos aditivos estudados.

Após o abate, foi coletado um segmento de $10 \mathrm{~cm}$ do jejuno, padronizado a $20 \mathrm{~cm}$ da Alça de Treitz, aberto em sua borda mesentérica, lavado, estendido pela túnica serosa e fixado em solução de Bouin, para ser submetido à análise morfométrica quanto à espessura da mucosa, da camada muscular e parede total. Depois de 3 a 4 horas na solução de Bouin, as amostras foram reduzidas a fragmentos de $0,5 \mathrm{~cm}$. Após permanecer por mais 24 horas na solução fixadora, foram lavadas em álcool etílico a $70^{\circ} \mathrm{GL}$ e, em seguida, desidratadas em uma série crescente de álcoois. Após a desidratação, foram diafanizadas em xilol e incluídas em parafina, para se obterem cortes transversais de $5 \mathrm{~mm}$ da parede intestinal, sendo, posteriormente, corados pela técnica de Hematoxilina Eosina de Harris.

Para as análises morfométricas da parede do jejuno, foram realizadas 40 medidas de espessura da túnica mucosa (que compreende desde a ponta do vilo, até à túnica muscular da mucosa) e da túnica muscular externa (que compreende a túnica muscular circular e a longitudinal) e 30 medidas da parede total (que compreende desde a ponta do vilo até à túnica serosa) para cada lâmina, utilizando-se um sistema analisador de imagem (IMAGE - PRO PLUS), versão 4.1 (MEDIA CYBERNETICS ${ }^{\circledR}$ ). Algumas amostras foram documentadas por fotomicrografias, com câmera Olympus PMC 35b, conectada a um microscópio P1 Olympus BX 50.

\section{Ensaio de crescimento}

Para o ensaio de crescimento, foram utilizados 176 coelhos da raça Nova Zelândia Branco, 88 machos e 88 fêmeas, no período de 35 a 75 dias de idade, alojados em gaiolas de arame galvanizado, providas de bebedouro automático e comedouro semi automático de chapa galvanizada, localizados em galpão de alvenaria, com cobertura de telha francesa, pé-direito de 3,0 metros, piso de alvenaria, paredes laterais de $50 \mathrm{~cm}$ em alvenaria e o restante, em tela e cortina de plástico para controle de ventos.

A temperatura média registrada durante o experimento foi de $23^{\circ} \mathrm{C}$, sendo que a máxima e a mínima registradas foram de 26 e $20^{\circ} \mathrm{C}$, respectivamente.

$\mathrm{O}$ delineamento experimental utilizado foi inteiramente casualizado, com oito tratamentos, 11 repetições e dois animais por unidade experimental. Os tratamentos foram os mesmos dos experimentos anteriores.

As rações, peletizadas a seco e a água foram fornecidas à vontade. A partir dos 60 dias de idade até o abate (75 dias de idade), os animais passaram a receber a dieta referência, sem suplementação de qualquer um dos aditivos estudados.

Os animais foram pesados no início do experimento ( 35 dias de idade), aos 50 dias, aos 60 dias e no final do experimento (75 dias de idade).

Os pesos e rendimento das carcaças foram obtidos com as carcaças quentes com cabeça e sem as vísceras comestíveis. Também, no momento do abate, foram obtidos os pesos dos rins, fígado e do coração.

\section{Análise estatística}

A análise estatística das variáveis estudadas foi realizada, utilizando-se o procedimento GLM do programa estatístico SAS (1985) e o modelo estatístico utilizado para a análise dos coeficientes de digestibilidade e para o desempenho foi:

$$
\mathrm{Y}_{\mathrm{ij}}=\mu+\mathrm{D}_{\mathrm{i}}+\mathrm{e}_{\mathrm{ij}}
$$

em que $\mathrm{Y}_{\mathrm{ij}}=$ variáveis estudadas obtidas com o indivíduo $j$, recebendo a dieta $i$; $\mu=$ constante geral; $\mathrm{D}_{\mathrm{i}}=$ efeito da dieta $\mathrm{i}(\mathrm{i}=1$ a 8$) ; \mathrm{e}_{\mathrm{ij}}=$ erro aleatório

\section{R. Bras. Zootec., v.31, n.6, p.2227-2237, 2002}


associado a cada observação $\mathrm{Y}_{\mathrm{ij}}$.

Utilizou-se o peso inicial como covariável para a análise das variáveis de desempenho.

Para a análise das características morfométricas do jejuno, incluiu-se no modelo o efeito da idade.

As médias foram comparadas, utilizando-se o teste de Tukey a $5 \%$.

\section{Resultados e Discussão}

\section{Ensaio de digestibilidade}

Não foram observadas diferenças $(\mathrm{P}>0,05)$ sobre os coeficientes de digestibilidade aparente da matéria seca, da matéria orgânica, da proteína bruta, da fibra detergente neutro e da energia bruta entre os tratamentos (Tabela 2).

De acordo com vários autores (De Blas, 1984; Cromwell, 1989; Fuller, 1989; Kermauner \& Strucklec, 1996), aditivos utilizados em dietas, como probiótico, ácidos orgânicos e antibióticos atuam controlando a proliferação de microrganismos patógenos, favorecendo a proliferação de microrganismos desejáveis e/ou atuando sobre o $\mathrm{pH}$ do trato digestivo. Como resultado, diminui os distúrbios gastrointestinais e melhora o aproveitamento dos nutrientes e o desempenho dos animais.

Neste sentido, deve-se salientar que não foi registrada presença de distúrbios digestivos durante o experimento, nem mesmo entre os animais que receberam a dieta controle, sem qualquer aditivo. Possivelmente, as boas condições sanitárias e ambientais durante a condução do experimento tenham sido a causa da falta de resposta, em relação ao uso dos aditivos sobre a melhoria na disponibilidade dos nutrientes. A literatura mostra resultados conflitantes, que podem estar relacionados com a composição dos probióticos, as condições sanitárias do rebanho, as condições ambientais, a fase fisiológica dos animais e as características das dietas, particularmente, a composição em carboidratos solúveis e sua relação com outros nutrientes.

Hollister et al. (1989), suplementando dietas de coelhos em crescimento com Lacto-Sacc ${ }^{\circledR}$ ou Acid Pak-4-Way, este último contendo em sua composição, entre outros microrganismos, Bacillus subtilis, também não observaram efeitos sobre os coeficientes de utilização digestiva de nutrientes. Contudo, Yamani et al. (1992), utilizando Acid Pak-4-Way, observaram melhora sobre os coeficientes de digestibilidade da fibra bruta e proteína bruta, em coelhos entre sete e 12 semanas de idade, sendo que, a partir da $13^{\mathrm{a}}$ semana, melhores resultados foram observados somente sobre a digestibilidade da fibra bruta. Zoccarato et al. (1995) também observaram maiores coeficientes de utilização digestiva da matéria seca, matéria orgânica e proteína bruta com dietas para coelhos, suplementadas, com um probiótico à base de Bacillus subtilis + Bacillus licheniformes.

Com relação ao uso de ácidos orgânicos, Radecki et al. (1988) também não encontraram efeitos da adição de $1,5 \%$ de ácido fumárico às dietas sobre o balanço de nutrientes em suínos. Da mesma forma, Eidelsburger et al. (1992) não observaram efeitos da adição de $1,8 \%$ de ácido fumárico às dietas sobre a utilização de nutrientes, apesar da dieta com ácido fumárico ter proporcionado melhora no ganho de peso diário e na conversão alimentar.

\section{Morfometria intestinal}

Não foram observadas diferenças $(\mathrm{P}>0,05)$ para as medidas morfométricas da parede do jejuno dos coelhos (Tabela 3).

Embora o probiótico utilizado tenha sido diferente (LBC ME $10^{\circledR}$ - Enterococcus faecium Cernelle 68; 40 g/t) Loddi (1998) também não observou diferença na altura dos vilos e profundidade de cripta do jejuno em frangos de corte.

Por outro lado, Lima et al. (2000), analisando a morfometria do duodeno de frangos de corte, suplementados com o probiótico Calsporin- $10^{\circledR}$, obtiveram aumento na altura da vilosidade e na profundidade da cripta.

Dobrogoszet al. (1991) observaram aumento, tanto no comprimento do vilo, como na profundidade de cripta no intestino delgado de frangos de corte, em que as dietas foram suplementadas com Lactobacillus reuteri.

Fica claro que a ação dos probióticos, tanto em características de desempenho, como histológicas do trato digestivo, dependem, basicamente, da composição do produto e, segundo Fuller (1989), das características e sua relação com os microrganismos presentes no trato digestivo das diferentes espécies.

Tournut (1998) também ponderam que os efeitos benéficos de probióticos podem aparecer a partir de um determinado tempo, necessário para que o agente se estabeleça no trato digestivo e equilibre a flora.

Apenas a espessura da camada mucosa diminuiu linearmente $(\mathrm{P}<0,05)$ com o aumento da idade dos coelhos (Tabela 3), apesar do baixo coeficiente de relação. 


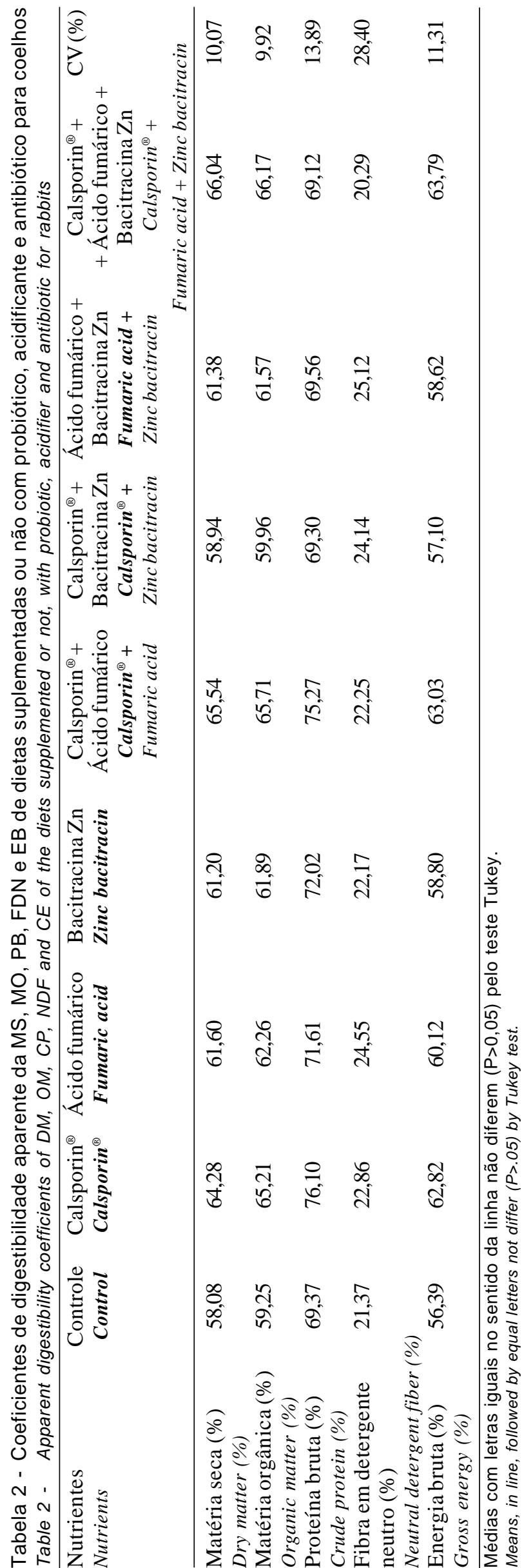

\section{Ensaio de crescimento}

A utilização de Calsporin-10 ${ }^{\circledR}$, ácido fumárico ou bacitracina de zinco, isolados ou combinados, não influenciaram $(\mathrm{P}>0,05)$ o desempenho dos animais no período de 35 a 50 dias de idade (Tabela 4). Deve-se salientar que, apesar desta fase ser a mais crítica quanto à incidência de distúrbios digestivos, nenhum caso de diarréia foi observado, nem mesmo com os animais recebendo a dieta referência, contribuindo para mortalidade zero durante o período experimental. As boas condições ambientais e o bom estado sanitário dos animais, possivelmente, tenham contribuído para os resultados obtidos.

Considerando o período total do experimento de 35 a 75 dias de idade (Tabela 4), a dieta, contendo ácido fumárico combinado com bacitracina de zinco, proporcionou os melhores resultados de peso vivo aos 75 dias de idade e ganho de peso médio diário, diferenciandose $(\mathrm{P}<0,05)$ dos animais alimentados com as dietas controle e com as dietas contendo somente bacitracina de zinco ou a combinação do probiótico Calsporin- $10^{\circledR}$ com bacitracina de zinco, que apresentaram os piores resultados. Observação semelhante pode ser constatada para a conversão alimentar. O consumo de ração, por sua vez, não foi influenciado $(\mathrm{P}>0,05)$ pela inclusão dos aditivos, independente de serem utilizados, isoladamente ou combinados.

Analisando os resultados de desempenho, observase que a melhora deve-se à adição do ácido fumárico isoladamente ou em combinação, tanto com o probiótico Calsporin- $10^{\circledast}$, como com a bacitracina de zinco.

Zaghini et al. (1986a) também obtiveram maior ganho de peso e melhora na conversão alimentar de coelhos, recebendo dietas com 2,0\% de ácido fumárico.

Por outro lado, Scapinello et al. (1998), trabalhando com coelhos em crescimento e suplementando dietas até 2,0\% de ácido fumárico e Henrique et al. (1998), utilizando 5,0 kg de ácido fumárico/tonelada de ração para frangos de corte, não observaram diferenças no desempenho dos animais.

Com relação ao uso de probióticos, Lambertini et al. (1990), utilizando um probiótico à base de Bacillus subtilis, similar ao produto usado neste experimento, e Kermauner \& Struklec (1996), utilizando Acid Pak-4-Way, em que o Bacillus subtilis faz parte de sua composição, entre outros microrganismos e enzimas, também não obtiveram resposta no desempenho de coelhos.

Diferentemente dos resultados de desempenho obtidos neste trabalho, particularmente se consideradoo 
MICHELAN et al.

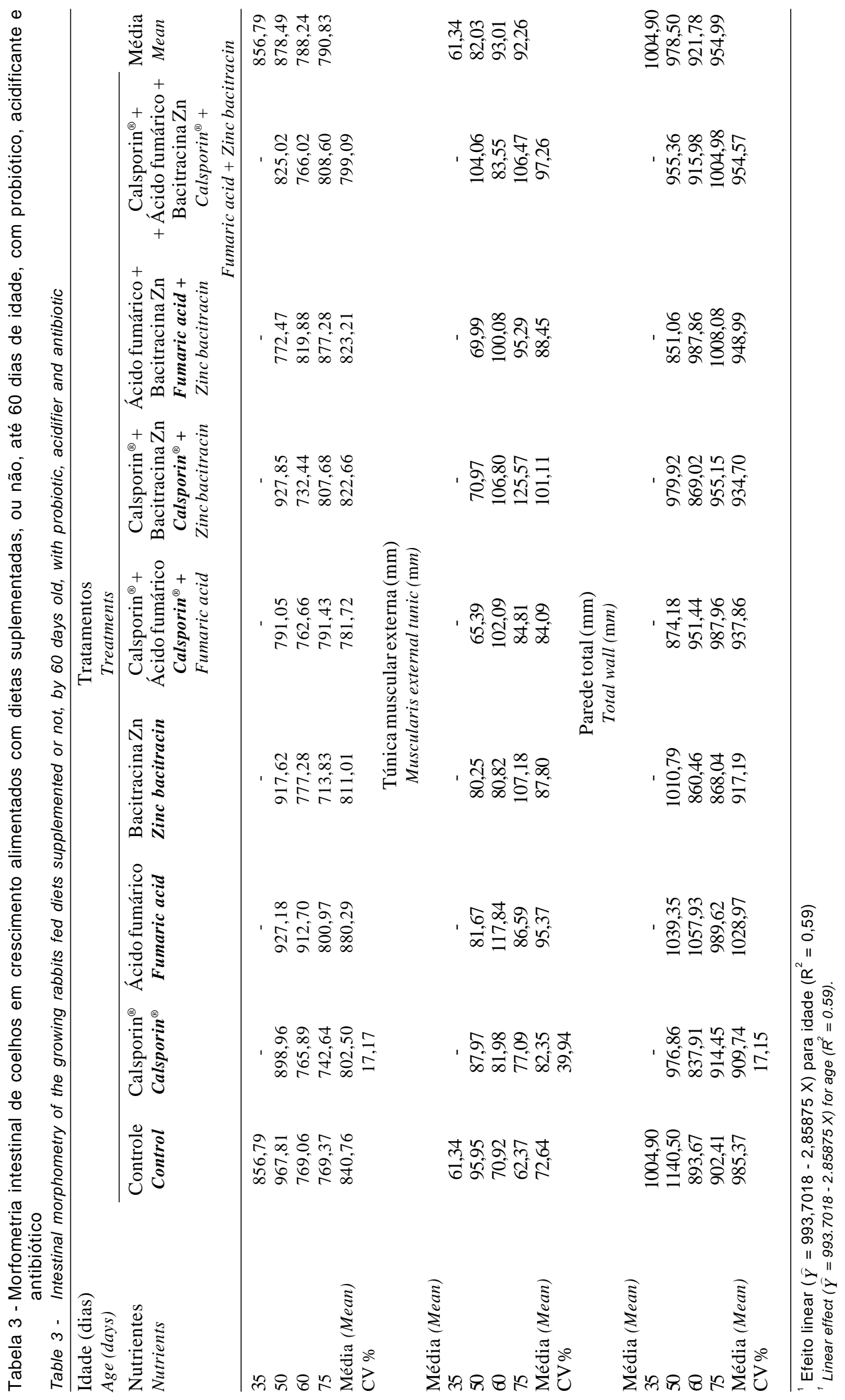




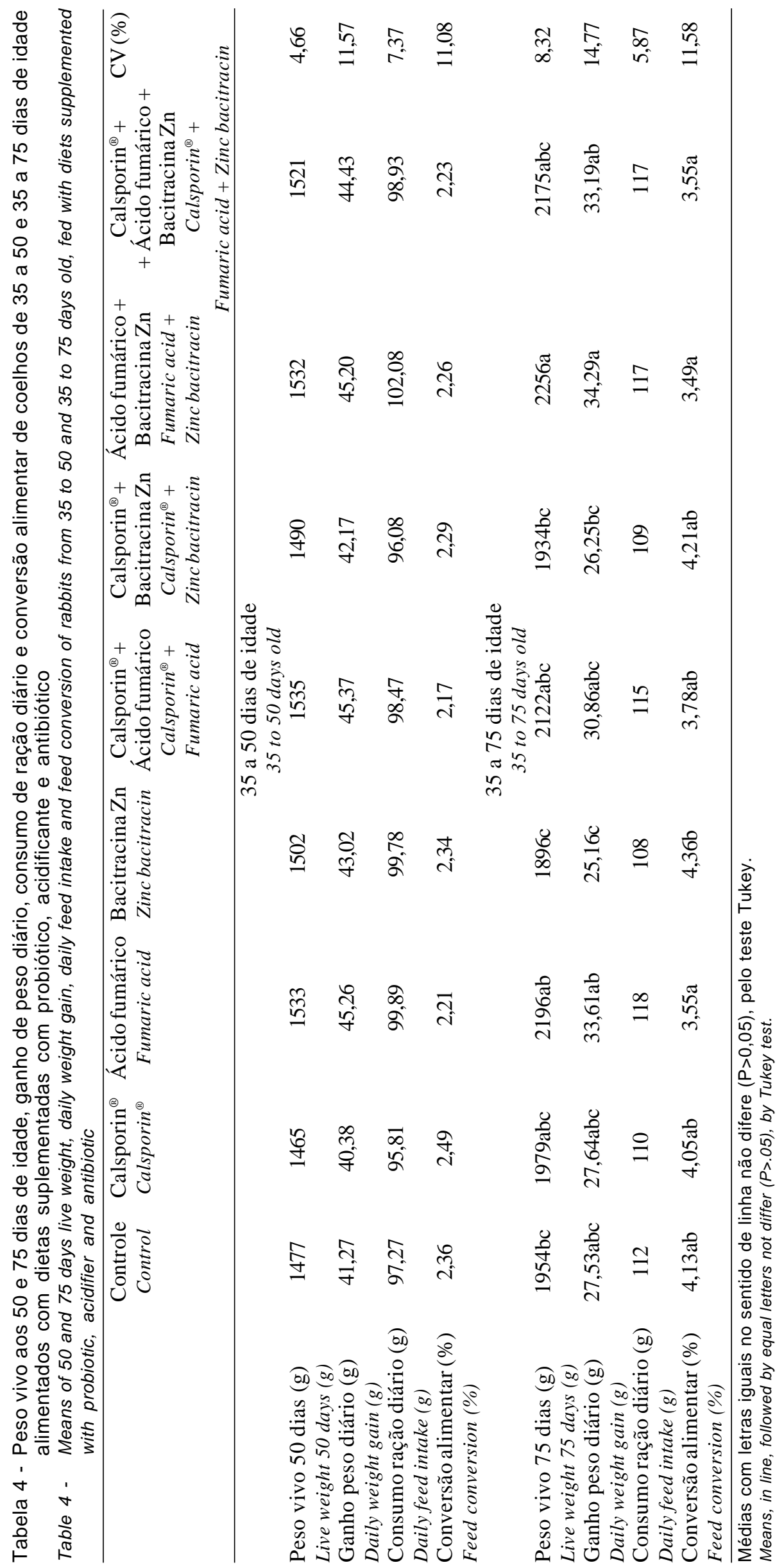


período total Abdel-Samee (1995), utilizando bacitracina de zinco, observou melhora no ganho de peso e no consumo de ração quando adicionada em 150 ppm em dietas de coelhos em crescimento. Da mesma forma, quando utilizada em combinação com outro antibiótico (100 ppm de Bacitracina de zinco + 60 ppm de Apramicina), Gutiérrez et al. (2000) também observaram melhora no ganho de peso de coelhos. Os autores destacam, no entanto, que a resposta positiva foi mais evidente em animais mais jovens e mantidos em ambientes não adequados. Com relação à fase de desenvolvimento, evidência semelhante pode ser observada nos resultados do presente trabalho.

As médias estimadas do peso e rendimento de carcaça quente com cabeça e dos pesos do fígado, rins e coração encontram-se na Tabela 5.

Os melhores resultados, tanto para o peso, como para o rendimento de carcaça, foram observados para coelhos que receberam as dietas suplementadas apenas com o ácido fumárico, ou, então, quando combinado com a bacitracina de zinco, diferindo $(\mathrm{P}<0,05)$, no entanto, apenas da dieta com o uso do probiótico Calsporin ${ }^{\circledR}$, cujos resultados foram os mais baixos.

Não foram observadas diferenças $(P>0,05)$ para peso das vísceras comestíveis entre os tratamentos. Os resultados da avaliação quantitativa da carcaça estão relacionados com o desempenho dos animais, onde os que tiveram maior peso ao abate, normalmente apresentam as carcaças mais pesadas e com maior rendimento.

Zaghini et al. (1986b), semelhantemente ao observado neste trabalho, também obtiveram maior rendimento de carcaça de coelhos alimentados com dietas suplementadas com 2,0\% de ácido fumárico.

\section{Conclusões}

A suplementação das dietas com o probiótico Calsporin- $10^{\circledR}$, ácido fumárico e bacitracina de zinco, isolados ou combinados, não influenciou a utilização digestiva dos nutrientes e nem as características morfométricas do jejuno. No entanto, a espessura da túnica mucosa diminuiu linearmente com o aumento da idade dos coelhos.

Os coelhos que receberam as dietas suplementadas com ácido fumárico isolado, ou combinado com bacitracina de zinco, apresentaram os melhores resultados de desempenho, no período total do experimento ( 35 a 75 dias de idade). Estas mesmas dietas também foram as que proporcionaram os melhores resultados de peso e rendimento de carcaça.

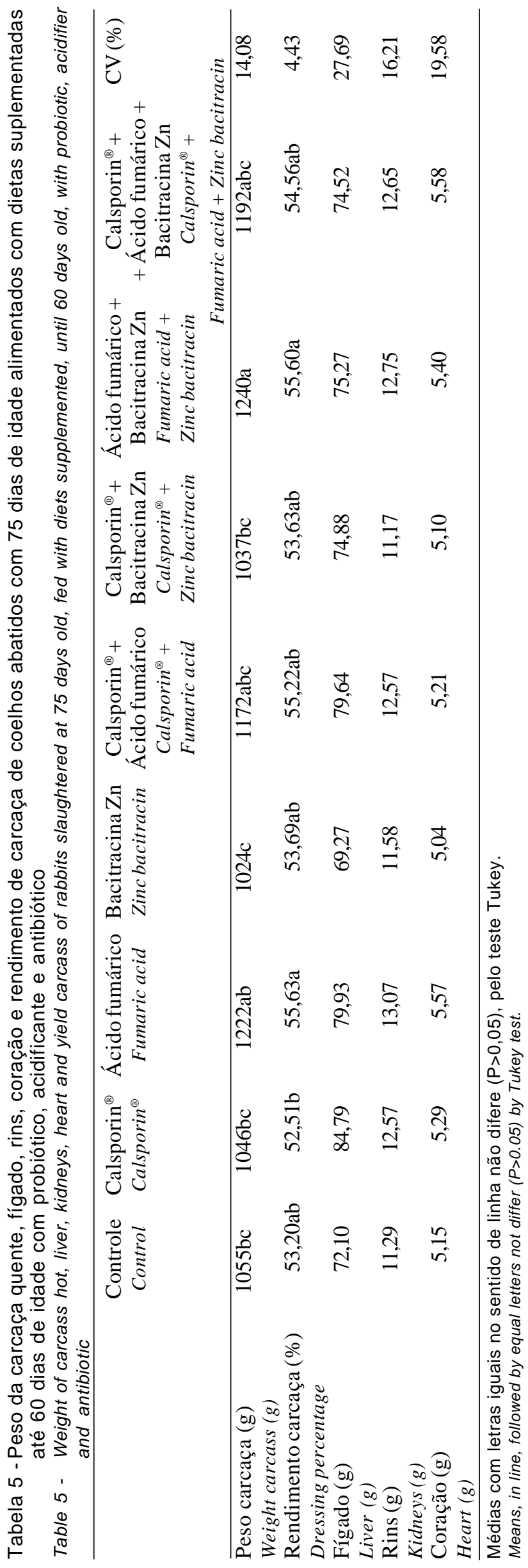

R. Bras. Zootec., v.31, n.6, p.2227-2237, 2002 


\section{Literatura Citada}

ABDEL-SAMEE, A.M. Using some antibiotics and probiotics for alleviating heat stress on growing and does rabbits in Egypt. World Rabbit Science, v.3, n.3, p.107-111, 1995.

CROMWELL, G.L. Nuevos aditivos alimentícios. Ind. Porc., v.9, n.6, p.14-15, 1989.

De BLAS, C. Alimentación del conejo. Madri: Mundi-Prensa, 1984. $215 \mathrm{p}$.

DOBROGOSZ, W.J.; BLACK, B.L.; CASAS, I. A. Delivery of viable Lactobacillus reuteri to the gastrointestinal tract of poultry. Poultry Science, n.70, p.158, 1991.

EIDELSBURGER, U.; KIRCHGESSNER, M.; ROTH, F.X. Influence of fumaric acid, hydrochloric acid, sodium formate, tylosin and toyocerin on daily weigth gain, feed intake, feed conversion rate and digestibility. II. Investigations about the nutritive efficacy of organic acids in the rearing of piglets. Journal of Animal Physiology Animal Nutrition, v.68, n.2, p.82-92, 1992.

FULLER, R. Probiotics in man and animals: a review. Journal of Applied Bacteriology, n.66, p.365-378, 1989.

FRITTS, C.A.; KERSEY, J.H.; MOTL, M.A. et al. Bacillus subtilis C 3102 (Calsporin) improves live performance and microbiological status of broiler chickens. Journal of Applied Poultry Research, v.9, n.2, p.149-155, 2000.

GIDENNE, T. Caeco-colic digestion in the growing rabbit: impact of nutritional factores and related disturbances. Livestock Production Science, n.51, p.73-88, 1997.

GUTIÉRREZ, I., GARCIA, P., CARABAÑO, R. et al. 2000. Effect of supplementation with animal plasma and antibiotics on jejunal morphology of early-weaned rabbits. In: WORLD RABBIT CONGRESS, 7., 2000, Valencia. Proceedings... Valencia: 2000. p.263-267.

HENRIQUE, A.P.F.; FARIA, D.E.; NETO, R.F. et al. Uso de probióticos, antibióticos e ácidos orgânicos como promotores de crescimento para frangos de corte. In: CONFERÊNCIA APINCO DE CIÊNCIA E TECNOLOGIA AVÍCOLAS, 1998. Campinas. Anais... Campinas: FACTA ( Fundação Apinco de Ciência e Tecnologia Avícola), 1998. p.31.

HOLLISTER, A.G.; CHEEKE, P.R.; ROBINSON, K.L. et al. Effects of water-administered probiotics and acidifiers on growth, feed conversion and enteritis mortality of weanling rabbits. Journal of Applied Rabbit Research, n.12, p.143-147, 1989.

KERMAUNER, A.; STRUKLEC, M. Addition of probiotic to feeds with different energy and ADF content in rabbits. 1. Effect on the digestive organs. World Rabbit Science, v.4, n.4, p.187-193, 1996.

LAMBERTINI, L.; ZAGUINI, G.; DAMMACCO, D. Risultati acquisiti com l'impiego di Bacillus subtilis in mangini per conigli. Rivista di Coniglicoltura, n.5, p.29-32, 1990.

LAPLACE, J.P. Le transit digestif chez les monogastriques. III - Comportement (prise de nourriture, caecotrophie), motricité et transit digestif et pathogénie des diarrhéas chez le lapins. Annales de Zootechnie, n.27, p. 225-265, 1978.

LEBAS, F. Besoins nutritionnels des lapins: revue bibliographique et perspectives. Cuniculture Science, v.5, n.2, p.1-28, 1989.

LIMA. A.C.F.; HARNICH, F.R.; PIZAURO, J.M. et al. Suplementação enzimática e/ou probiótica na ração sobre a atividade de enzima e morfometria intestinal de frangos de corte criados no calor. Revista Brasileira de Ciência Avícola, n.2, p. 52-53, 2000.

LODDI, M.M. Aspectos produtivos e qualitativos do uso de probiótico para frangos de corte. Botucatu: Universidade Estadual Paulista, 1998. 60p. Dissertação (Mestrado em Zootecnia) - Universidade Estadual Paulista, 1998.
MACARI, M., MAIORKA, A. Função gastrintestinal e seu impacto no rendimento avícola. In: CONFERÊNCIA APINCO DE CIÊNCIA E TECNOLOGIA AVÍCOLAS, 2000, Campinas. Anais...Campinas: FACTA( Fundação Apinco de Ciência e Tecnologia Avícola), 2000. p.161.

PEREZ, J.M.; LEBAS, F.; GIDENNE, T. et al. European reference method for in vivo determination of diet digestibility in rabbits. World Rabbit Science, v.3, n.3, p.41-43, 1995.

PHILLIP, L.E.; FELLNER, V. Effects of bacterial inoculation of high-moisture ear corn on its aerobic stability, digestion, and utilization for growth by beef steers. Journal of Animal Science, n.70, p.3178-3187, 1992.

POLLMAN, O.S. Probiotics in pig diets. In: RECENT ADVANCE IN ANIMAL NUTRITION, 12., 1986, London. Proccedings... London: 1986. p.88.

RADECKI, S.V.; JUHL, M.R.; MILLER, E.R. Fumaric and citric acids as feed additives in starter pig diets: effect on performance and nutrient balance. Journal of Animal Science, v.66, n.10, p.2598-2605, 1988.

SCAPINELLO, C.; BANTES, V.; FARIA, H.G. et al. Efeito de diferentes níveis deácido fumárico sobre o desempenho de coelhos em crescimento. In: REUNIÃO ANUAL DA SOCIEDADE BRASILEIRA DEZOOTECNIA, 34, 1997, Juiz de Fora. Anais... Juiz de Fora: Sociedade Brasileira de Zootecnia, 1997. p.215.

SCAPINELLO, C.; FARIA, H.G.; FURLAN, A.C. et al. Influência de diferentes níveis de ácido fumárico ou acético sobre o desempenho de coelhos em crescimento. Revista Brasileira de Zootecnia, v.27, n.5, p.945-950, 1998.

STATISTICAL ANALYSIS SYSTEM. SAS User's guide: statistics. 5.ed. Cary: 1985. 592p.

SILVA, D.J. Análise de alimentos (métodos químicos e biológicos). Viçosa, MG: Universidade Federal de Viçosa, 1990. 165p.

TOURNUT, J.R. Probiotics. In: REUNIÃO ANUAL DA SOCIEDADE BRASILEIRA DE ZOOTECNIA, 35., 1998, Botucatu. Anais... Botucatu: Sociedade Brasileira de Zootecnia, 1998. p.179-199.

YAMANI, K.A.; IBRAHIM, H.; RASHWAN, A.A. et al. Effects of a pelleted diet supplemented with probiotic (Lacto-Sacc) and water supplemented with a combination of probiotic and acidifier (Acid Pak-4-Way) on digestibility, growth, carcass and physiological aspects of weanling New Zealand White rabbits. Journal of Applied Rabbit Research, n. 15, p.1087-1100, 1992.

YU, B.; CHIOU, P. W. S. The morphological changes of intestinal mucosa in growing rabbits. Lab. Animal, n.31, p.254-263, 1997.

ZAGHINI, G.; LAMBERTINI, L.; BONDIOLI, A. Ulteriori indagini su ruolo ed efficacia di acidi organici introdotti in alimenti per conigli da carne. Zootec. Nutr. Anim., v.12, n.5, p.357-366, 1986a.

ZAGHINI, G.; LAMBERTINI, L.; RIZZI, L. et al. Osservazioni sull'impiegodiacidofumaricoinalimentiperconigliinaccrescimento. Zootec. Nutr. Anim., v.12, n.2, p. 143-151, 1986b.

ZOCCARATO, I.; BARBERA, S.; TARTARI, E. Effetto dell'impiego di mangime contenente un' associazione antibioticoprobiotico sulle performance del coniglio all'ingrasso. Zootec. Nutr. Anim., v.21, n.5, p. 297-304, 1995.

ZUANON, J.A.S.; FONSECA, J.B.; ROSTAGNO, H.S. et al. Desempenho de frangos de corte alimentados com rações contendo antibiótico e probiótico adicionados isoladamente, associados e em uso seqüencial. Revista Brasileira de Zootecnia, v.27, n.5, p.994-998, 1998.

Recebido em: 22/10/01 Aceito em: 05/08/02

R. Bras. Zootec., v.31, n.6, p.2227-2237, 2002 